\title{
COPD and Physical Activity: A Call to Action for Respiratory Therapists and Patients
}

An estimated 15 million people in the United States have been told they have COPD by a healthcare provider. ${ }^{1}$ COPD is the third leading cause of death ${ }^{2}$ and accounts for more than 800,000 hospitalizations per year. ${ }^{3}$ A robust proportion $(10-20 \%)$ of individuals with COPD are readmitted to the hospital within $30 \mathrm{~d}$ after their discharge, contributing to the rising health care cost of treating COPD, which is expected to reach $\$ 49$ billion by $2020 . .^{4-6}$ Together, these data suggest that we must identify effective treatment strategies to improve the burden of COPD. This editorial expands on the article by Mussa et $\mathrm{al}^{7}$ in this issue of Respiratory CARE and proposes a call to action to respiratory therapists for increasing our activity in research aimed at improving the burden of COPD.

Widely accepted treatment for COPD includes pharmacotherapy and oxygen. Another well-established standard of care for individuals with COPD is pulmonary rehabilitation. In a 2015 report, the American Thoracic Society and the European Respiratory Society announced a policy statement that pulmonary rehabilitation provides physiological, psychosocial, symptom reducing, and health economic benefits to individuals with COPD. ${ }^{8}$ Moreover, the report recommends long-term adherence to physical activity as an important component of pulmonary rehabilitation. ${ }^{8}$ However, due to the lack of evidence and mixed methodological approaches of previous studies, we can only infer that pulmonary rehabilitation has the potential for generating a positive impact on physical activity levels. In addition, it's still unknown whether increasing physical activity level in COPD patients will improve mortality. ${ }^{9}$ To strengthen the recommendation for physical activity, we must improve the quality of evidence of studies incorporating this important outcome measure. As a result, the European Respiratory Society concluded that there is an urgent need for more well-designed studies aimed to re-

The author has disclosed no conflicts of interest.

Correspondence: Dave Burnett $\mathrm{PhD}$, Respiratory Care Education, Mailstop 1013, University of Kansas Medical Center, 3901 Rainbow Boulevard, Kansas City, Kansas 66160. E-mail: dburnett@kumc.edu.

DOI: $10.4187 /$ respcare.05992 port on the effectiveness of interventions on physical activity in individuals with COPD. ${ }^{9}$

From this background, efforts should be made to become more actively engaged in research focused on the

\section{See the Original Study on Page 11}

knowledge gap remaining in the area of physical activity and COPD. Mussa et $\mathrm{al}^{7}$ contributes to this knowledge gap and has clinical consequence. We should applaud the authors for introducing a significant starting point, as the data in their study were collected from a robust sample of COPD subjects $(N=417)$ to help answer outcomes important to individuals with COPD. The researchers determined that COPD subjects' perception of a long-term oxygen therapy (LTOT) delivery device significantly affected their perceived mobility. The authors were also able to imply that perceived mobility positively affected quality of life, an important patient-centered outcome in individuals with COPD. The results of the article by Mussa et $\mathrm{al}^{7}$ inform clinicians and researchers about ways to better approach future work focusing on improving the lives of those living with COPD. In all, the authors should be congratulated on their approach to assess a robust number of subjects to allow for meaningful results and filling an important knowledge gap.

The objective of the article by Mussa et $\mathrm{al}^{7}$ was to determine the impact of LTOT device satisfaction on mobility and quality of life in COPD subjects. It is expected that a decrease in mobility can relate to a reduction in physical activity. Physical activity has shown to be associated with higher overall mortality in the elderly. ${ }^{10,11}$ Past research also suggests that COPD patients voluntarily limit their activity early in their disease process. ${ }^{12-14}$ Another study reported that only $26 \%$ of COPD subjects achieved the recommended daily physical activity level. ${ }^{15}$ This reduction in physical activity has negative consequences, as individuals with COPD perceived their physical activity level to affect their quality of life. ${ }^{16}$ From an economic perspective, low physical activity levels have been shown to be inversely related to COPD-related hospitalizations. ${ }^{17,18}$ Although we're learning more about the needs of individuals with COPD, many questions still remain 


\section{EDITORIALS}

unanswered, and more work is required to reduce the physical and economic burden of COPD.

There must be a call to action for more respiratory therapists to support the scientific community with additional evidence directed at safe and effective treatment for individuals with COPD. More respiratory therapists are needed to fill roles in academic and research environments to contribute to important knowledge gaps in our field. As respiratory therapists produce more work adding to our scientific body of knowledge, we can become an increasingly vital contributor to clinical practice guidelines and policy change for our patients. More important, scholarly activity such as that published by Mussa et $\mathrm{al}^{7}$ will help us improve patient care.

\section{David M Burnett PhD RRT AE-C University of Kansas Medical Center} Kansas City, Kansas

\section{REFERENCES}

1. Centers for Disease Control and Prevention. Chronic obstructive pulmonary disease among adults: United States, 2011. MMWR Morb Mortal Wkly Rep 2012;61(46):938-43.

2. Kochanek KD, Xu J, Murphy SL, Minino AM, Kung HC. Deaths: final data for 2009. Natl Vital Stat Rep 2011;60(3):1-116.

3. Wier LM Elixhauser A, Pfuntner A, Au DH. Overview of hospitalizations among patients with COPD. Healthcare Costs and Utilization Project (HCUP) Statistical Briefs 2011;106.

4. Bahadori K, FitzGerald JM. Risk factors of hospitalization and readmission of patients with COPD exacerbation-systematic review. Int J Chron Obstruct Pulmon Dis 2007;2(3):241-51.

5. Shah T, Churpek MM, Coca Perraillon M, Konetzka RT. Understanding why patients with COPD get readmitted: a large national study to delineate the Medicare population for the readmissions penalty expansion. Chest 2015;147(5):1219-26.

6. Sharif R, Parekh TM, Pierson KS, Kuo YF, Sharma G. Predictors of early readmission among patients 40 to 64 years of age hospitalized for chronic obstructive pulmonary disease. Ann Am Thorac Soc 2014;11(5):685-94.

7. Mussa C, Tonyan L, Chen Y, Vines D. Perceived satisfaction with long-term oxygen delivery devices affects perceived mobility and quality of life of oxygen- dependent individuals with COPD. Respir Care in press.

8. Rochester CL, Vogiatzis I, Holland AE, Lareau SC, Marciniuk DD, Puhan MA, et al. An official American Thoracic Society/European Respiratory Society policy statement: enhancing implementation, use, and delivery of pulmonary rehabilitation. Am J Respir Crit Care Med 2015;192(11):1373-86.

9. Watz H, Pitta F, Rochester CL, Garcia-Aymerich J, ZuWallack R, Troosters T, et al. An official European Respiratory Society statement on physical activity in COPD. Eur Respir J 2014;44(6): 1521-37.

10. Manini TM, Everhart JE, Patel KV, Schoeller DA, Colbert LH, Visser M, et al. Daily activity energy expenditure and mortality among older adults. JAMA 2006;296(2):171-79.

11. Matthews CE, George SM, Moore SC, Bowles HR, Blair A, Park Y, et al. Amount of time spent in sedentary behaviors and cause-specific mortality in US adults. Am J Clin Nutr 2012;95(2):437-45.

12. Gouzi F, Prefaut C, Abdellaoui A, Vuillemin A, Molinari N, Ninot $\mathrm{G}$, et al. Evidence of an early physical activity reduction in chronic obstructive pulmonary disease patients. Arch Phys Med Rehabil 2011; 92(10):1611-17.

13. Shrikrishna D, Patel M, Tanner RJ, Seymour JM, Connolly BA, Puthucheary ZA, et al. Quadriceps wasting and physical inactivity in patients with COPD. Eur Respir J 2012;40(5):1115-22.

14. Van Remoortel H, Hornikx M, Demeyer H, Langer D, Burtin C, Decramer M, et al. Daily physical activity in subjects with newly diagnosed COPD. Thorax 2013;68(10):962-63.

15. Donaire-Gonzalez D, Gimeno-Santos E, Balcells E, Rodriguez DA, Farrero E, de Batlle J, et al. Physical activity in COPD patients: patterns and bouts. Eur Respir J 2013;42(4):993-1002.

16. Burgel PR, Escamilla R, Perez T, Carre P, Caillaud D, Chanez P, et al. Impact of comorbidities on COPD-specific health-related quality of life. Respir Med 2013;107(2):233-41.

17. Moy ML, Teylan M, Weston NA, Gagnon DR, Garshick E. Daily step count predicts acute exacerbations in a US cohort with COPD. PLoS One 2013;8(4):e60400.

18. Pitta F, Troosters T, Probst VS, Spruit MA, Decramer M, Gosselink R. Physical activity and hospitalization for exacerbation of COPD. Chest 2006;129(3):536-44. 